\title{
Proteção Jurídica dos Cães de Guarda no Sul do Brasil: uma questão de empatia nascida nos Movimentos de Proteção do Animal não Humano
}

\section{Legal Protection to Watchdogs in South of Brazil: a question of empathy born of Non-Human Animal Protection Movements}

Fernanda Luiza Fontoura de Medeiros

Centro Universitário La Salle, Canoas - RS, Brasil

Leticia Albuquerque

Universidade Federal de Santa Catarina, Florianópolis - SC, Brasil

Resumo: O reconhecimento dos direitos dos animais é um processo em evolução. A Constituição Federal brasileira proíbe práticas cruéis contra os animais não humanos. Contudo, tem sido uma prática comum a contratação de cães de aluguel para realização de segurança privadas. Alugar cães de guarda ofende o princípio da dignidade da vida, pois os animais são mantidos em situações degradantes. Diferentes atores do movimento de proteção animal se uniram para banir a locação de cães de guarda para segurança. A questão mobilizou a sociedade através das redes sociais, por meio de ações que envolvem emoções, empatia e um processo de política de tolerância, solidariedade e reciprocidade.

Palavras-chave: Movimentos Sociais. Direitos Animais. Dignidade.
Abstract: the recognition of animal rights is an ongoing process. The Brazilian Federal Constitution prohibits cruel practices against non-human animals. However, it has become a common business practice the rental of dogs for asset security. Renting watchdogs offends the principle of the dignity of life. The animals were kept in degrading situation. Different actors were protagonists of the movement to protect watchdogs and joined each other in the fight to ban the rental of guard dogs for property security. The issue mobilized society through a social network, the basic emergency action packed emotions, empathy, and processes of political tolerance and of reciprocity.

Keywords: Social Movements. Animal Rights. Dignity.

Recebido em: 16/10/2015

Revisado em: 07/03/2016

Aprovado em: 09/03/2016 


\section{Introdução}

A relação entre o animal humano e o animal não humano não é recente e nem é (ou nem sempre foi) tranquila. Waal (2010, p. 188) provoca, nesse sentido, questionando que "[...] desde a infância, as pessoas sabem que os animais têm sentimentos e se importam com os outros, mas suprimem intencionalmente esse conhecimento[...]" e continua "[...] de que maneira e por que razão a metade das pessoas abandona essa convicção quando adquirem peitos ou barba é algo que jamais entenderei." (WAAL, 2010, p. 188).

Esse interagir marcado pela empatia, desaparece, para alguns, à medida que os anos se acumulam e os preconceitos e desconhecimentos acerca das intensas e marcantes sensações, percepções, consciência e, inclusive, inteligência que se fazem presente nos animais não humanos. São preconceitos como esses que, em tese, provocam atitudes e opiniões de desqualificação do animal não humano como "coisa", "propriedade", "objeto" e, em suma, definem um tratamento inumano.

No caso dos cães de aluguel, o exame de instauração de uma lei que proíbe a utilização desses cães para segurança, vigilância e guarda com fins lucrativos e comerciais institui-se como um campo de extrema riqueza, tanto para a análise do estado da arte do direito dos animais no Estado do Rio Grande do Sul, quanto abre veredas para a transformação de modos de encarar esses animais não humanos em seus processos de interação com o animal humano, assim como destaca o valor das mobilizações sociais da sociedade em prol de uma consideração ${ }^{1}$ e, inclusive, dos direitos aos animais. Não restam dúvidas com relação ao tratamento cruel a que animais, como esses de cães de guarda ${ }^{2}$ são expostos.

\footnotetext{
${ }^{1}$ Essa consideração passa, inclusive, por atitudes de empatia, de compaixão, extrapolando para processos de solidariedade, reciprocidade e, também, de dignidade e direitos institucionalmente estabelecidos (MEDEIROS, 2013).

${ }^{2}$ Urge ressaltar que, quando se faz referência à expressão "cães de guarda", trata-se de guarda patrimonial, ou seja, não se trata de proteção ou segurança do animal humano realizada pelo animal não humano e, sim, a utilização do animal não humano para proteção de bens materiais, por exemplo: canteiros de obras, terrenos baldios, fábricas, dentre outros.
} 
Maus-tratos que se fazem presente em todas as frentes, como o transporte inadequado, a falta de abrigo, as condições inapropriadas de trabalho nos diferentes locais de guarda e segurança, sem fazer referência à falta de tratamento por parte de equipe veterinária, o abandono, sem cuidado e aposentadoria e, inclusive, a morte por descarte de serviço, relatados por órgãos públicos de defesa ambiental, pelo Ministério Público e Secretarias Públicas ${ }^{3}$, ou por entidades de proteção animal. Constituemse em desserviço para a causa de proteção animal. Inúmeras pesquisas e movimentos teórico-práticos vêm corroborando com essa temática de direitos dos animais. Dentre esses, destacam-se, para fins deste estudo, Regan (1983), Sunstein e Nussbaum (2004), Habermas (2004), Souza (2008), Naconecy (2014), Felipe (2014), Waal (2010), Nussbaum (2008), Levai (2004), Medeiros (2013) e Albuquerque e Medeiros (2013).

Estudos na área de movimentos sociais, especialmente com destaque às redes (CASTELLS, 1999; AGUIAR, 2007; SCHERER-WARREN, 2006; MELUCCI, 1966; RHEINGOLD, 1996), vêm evidenciando tanto a dinâmica quanto o valor dessas redes sociais virtuais como áreas de aprendizado coletivo. Além dessa aprendizagem colaborativa e, acima de tudo, coletiva, insere-se toda uma criação e difusão, quase que imediata, de pautas, resoluções e ações a implementar ou questionar. Da mesma forma, são espaços-tempos flexíveis que se abrem para a disseminação tanto de conhecimento quanto de pautas a amplificar em termos interesses coletivos. Permitem, com isso, fortificar ou enfraquecer, muito rapidamente, movimentos, assim como delinear tendências presentes na sociedade, como as que se reconhece hodiernamente em relação aos cuidados com meio ambiente e com o direito dos animais. São ações rizomáticas que se espalham, de modo viral, no ambiente estrito do debate ou se disseminam nas relações sociais.

${ }^{3}$ Como é o caso da Secretaria Especial dos Direitos Animais do Munícipio de Porto Alegre, no Estado do Rio Grande do Sul, bem como a Diretoria de Bem-Estar Animal do Munícipio de Florianópolis, no Estado de Santa Catarina. 


\section{Desenvolvimento}

Ao refletir acerca do movimento de proteção animal, Donaldson e Kymlicka (2013, p. 5) provocam ao defender que sempre que o movimento de defesa animal começa a ameaçar os interesses econômicos, aqueles que utilizam os animais - instrumentalmente - iniciam uma mobilização com o intuito de desacreditar o movimento, catalogando os defensores como radicais, extremistas e até terroristas. Afirmam, ainda, que não se surpreendem com a ineficiência dos movimentos de proteção dos animais não humanos em face de todos os obstáculos culturais e econômicos que devem ser transpostos.

A situação não é diferente com o concernente aos cães locados para prestação de serviços de vigilância, ou seja, aluguel de cães de guarda. Instantaneamente um novo negócio surge - incrivelmente lucrativo - com pouco ou quase nenhum risco ao empreendedor. Ao invés de contratar vigilantes e/ou seguranças (animais humanos) para realizarem a prestação do serviço de vigilância, se passa a "contratar" cães. Numa lógica perversa, e extremamente rentável, se deixa - enquanto empresário - de se preocupar com direitos trabalhistas, como: remuneração salarial (água e comida); descanso semanal remunerado (inexistente); férias (inexistente); fundo de garantia por tempo de serviço (inexistente); periculosidade (inexistente); insalubridade (inexistente); aposentadoria (morte).

Em uma prática cruel e arcaica, a coisificação de seres vivos - no caso, os animais não humanos - leva a um total descaso com o bem-estar dos cães, que são usados de acordo com os interesses humanos e descartados quando são considerados desnecessários ou incapazes de realizar suas atividades. Adam Smith $(1937$, p. 9) anuncia uma frase irreparável que defende que

[...] por mais egoísta que se possa admitir que seja o homem, é evidente que existem certo princípios em sua natureza que o levam a interessar-se pela sorte dos outros e fazem com que a felicidade destes lhe seja necessária, embora disso ele nada obtenha que não o prazer de testemunhar. 
Essa sorte dos outros necessariamente não precisa ser a sorte dos outros homens. Por que não enfrentar a ideia de que, sim, há homens que se preocupam com o bem-estar e a felicidade de outras espécies? Talvez a maior dificuldade esteja vinculada ao fato da uma notória dificuldade, enquanto espécie, de se enxergar como animais. De Waal (2010, p. 33) afirma, em um trecho de uma de suas obras, que acredita "[...] que somos animais, enquanto outras pessoas acreditam que somos algo inteiramente diferente". A pergunta que reverbera é que outra coisa seria essa?

Rollin (2006, p. 111), sustentando a discussão entre o Direito e a Moral, reflete que se estar vivo é a base para ser um sujeito moral e partir desse ponto sustentar todos os demais interesses, incluindo os direitos, não há como negar que os animais não humanos são sujeitos morais. O cenário ao qual se propõe a refletir envolve o abandono dos cães em canteiros de obra, em terrenos baldios, em empresas (houve época que em empresas públicas ${ }^{4}$ e particulares), sem proteção, sem água limpa, sem alimentação. Assim, houve um movimento em defesa da felicidade, em defesa dos direitos de outros seres, em defesa dos cães.

\subsection{Cães de Aluguel, Estudos e a Proibição da Prestação de Serviços de Vigilância e Segurança via Locação de Cães de Guarda}

A descoberta do filão econômico a partir da exploração do animal não humano não é inovadora, nem surpreendente. O homem explora os animais das formas mais diferenciadas possíveis. Quando se reduz a análise apenas ao cão, nem mesmo assim é inovador. Esses animais são reproduzidos e vendidos há muito tempo. Nessa linha, Gordilho (2008, p. 12) assevera que

O tratamento e as atitudes que adotamos em relação aos animais ensejam enormes contradições, pois, a depender da cultura em que estejamos inseridos, podemos ser, ao mesmo tempo, amistosos com algumas espécies e cruéis com outras, acreditando sempre que a lei

\footnotetext{
${ }^{4}$ Cumpre ressaltar que, no município de Porto Alegre, no Estado do Rio Grande do Sul, por meio do Decreto n. 17.569, de dezembro de 2011, as empresas públicas de administração municipal e autarquias estão proibidas de contratar, subcontratar ou terceirizar serviço de cães de guarda.
} 
e a moralidade estão do nosso lado. Será mesmo que nós temos o direito de tratar os animais dessa maneira?

Na luta pela proteção dos cães, no sentido da manutenção do seu direito a uma vida digna, as organizações não governamentais de proteção animal e o Ministério Público têm envidado esforços para denunciar e buscar resguardar a vida desses animais. Uma vez que os cães utilizados para resguardar imóveis de terceiros, construções, dentre outras atividades, ficam sem qualquer assistência alimentar e veterinária, submetidos à violência e aos maus-tratos, sem contar o abandono social e a solidão a que são submetidos. Tal situação é completamente contrária à natureza de sua espécie podendo, pois, ser considerada ato de crueldade e maustratos, em ofensa direta às normas constitucionais que garantem o direito fundamental de proteção aos animais não humanos.

É nessa banda que Felipe (2008, p. 75-76) destaca a falta de cuidado, de proteção e de possibilidade de sobreviver com qualidade:

O respeito pela autonomia prática, ou liberdade física, humana e não-humana, significa a preservação: 1 . Da integridade física do sujeito; 2. Da mobilidade para buscar os meios de subsistência biológica, para si e seus dependentes; e 3. Das condições necessárias à interação social daquele indivíduo em sua comunidade natural. Para os humanos, liberdade, no sentido básico e fundamental, significa a não escravidão, o não-aprisionamento, a não subtração do espaço físico necessário aos cuidados de subsistência, o não-isolamento mental, o não-isolamento social. Violando-se esses limites, comete-se, contra os seres humanos, a maior das injustiças, pois os tratamos como escravos e coisas.

Quando se analisa a posição de Felipe com a situação dos animais não humanos utilizados para segurança, observa-se, facilmente, que os cães não mantêm sua integridade física, não possuem mobilidade, não interagem socialmente. Convém, ainda, salientar, apoiando-se no posicionamento de Levai (2004, p. 91), que 
Não se pode esquecer que o homem, ao domesticar animais e trazê-los para viver em sua companhia, assumiu obrigações morais para com eles. Um animal de estimação, principalmente no contexto urbano, estabelece vínculos afetivos em relação à comunidade familiar na qual se encontra inserido, merecendo viver dignamente nesse meio. Tanto é verdade que os gatos e os cães costumam demonstrar gratidão àqueles que os acolhem e alimentam. É imoral e criminoso o dono desfazer-se dessas criaturas depois que elas criam um laço de dependência em relação ao lar. [...] Afora isso, alguns tipos de cães (Rottweiller, Pit Bull, Fila, Dobermann, etc.) sofrem exagerados castigos físicos em sessões de adestramento, para que se tornem ferozes e agressivos. As consequências desse treinamento bélico, caso o animal escape da vigilância de seu dono e saia às ruas, costumam ser trágicas.

No ano de 2011 várias entidades de proteção animal em parceria com a Frente Parlamentar de Defesa Animal, construíram uma alternativa no intuito de proibir a prestação dos serviços de vigilância e segurança através da locação de cães de guarda. A alternativa se deu consubstanciada na elaboração de um Projeto de Lei (PL n. 462/11), de autoria do Deputado Paulo Odone. Não há como negar que muito contribuíram para a aprovação do Projeto de Lei a rede de proteção e de protetores, assim como representantes da sociedade civil sensíveis à causa animal, militantes, ativistas da causa do Direito dos Animais, que se mobilizaram através das redes sociais. Em 2013 foi aprovada a Lei n. 14.229, vetando a utilização dos animais como instrumentos de segurança patrimonial.

Essa Lei vem demarcar uma posição em termos de cuidado, proteção aos animais, assim como, sinalizar para a ampliação de um campo de direito, uma vez que reafirma, sob o ponto de vista da proteção do ordenamento jurídico brasileiro, essencialmente pela proteção fundamental da Constituição ${ }^{5}$, as atividades relacionadas à locação de cães não são permi-

\footnotetext{
${ }^{5}$ Segundo Medeiros e Rodrigues (2011), é de conhecimento público que essa mesma Constituição, em seu artigo $5^{\circ}$, inciso XIII, garante o livre exercício de qualquer trabalho, ofício ou profissão, atendidas as qualificações profissionais que a lei estabelecer. Importante frisar que, se fosse o caso, seria possível estar aqui diante de uma colisão de direitos fundamentais, situação que se vivencia diariamente em diversos outros setores (proteção
} 
tidas revertendo o modo de tratar os animais. Uma vez que as empresas que alugam cães para a realização das atividades de segurança, vigilância e guarda, tratam os animais como "coisas", bens, e, dessa forma, dispõem deles como objetos. Já nessa condição está presente, no mínimo, o desrespeito, pressupondo como se tal condição (bens/coisas/objetos) autorizasse a prática de maus-tratos e crueldade. Animais não humanos não são coisas, nem bens, nem objetos, e estão protegidos pela Constituição Federal (art. 225, $\S 1^{\circ}$, inciso VII), pela Lei n. 9.605/98 (art. 32), pela Lei Estadual n. 1.915/03 e, historicamente, pelo Decreto-Lei n. 24.465/34.

Urge destacar, ainda, que a Constituição Federal, em seu artigo 225, $\S 1^{\circ}$, inciso VII disciplina o direito e o dever fundamental de proteção ambiental (MEDEIROS, 2004), colocando-os a salvo de maus-tratos e crueldades. Como não existe hierarquia entre as normas constitucionais, é tarefa de o intérprete conciliar, ponderar, as normas que regulam o desenvolvimento econômico, o desenvolvimento social e a proteção do ambiente (incluído nele a proteção dos animais não humanos). Destaca-se a lição de Levai (2004, p. 137) que defende que:

[...] dentro dos princípios constitucionais da ordem econômica, relacionados no art. 170 da $\mathrm{CF}$, está o da defesa do meio ambiente, no qual se inclui a proteção aos animais. Isto porque a Constituição

da natureza e direito de propriedade; direito ao culto religioso e proteção dos animais; direito ao lazer e o trabalho aos domingos e feriados, dentre outros tantos), resolvidos, pelo Ordenamento Jurídico, por meio da ponderação e da aplicação do princípio da proporcionalidade em seu tríplice aspecto (adequação, necessidade e proporcionalidade em sentido estrito). Parece-nos que o presente PL não suporta o exercício da aplicação do princípio da proporcionalidade, haja vista, não ser adequado, nem necessário, nem proporcional. Desta feita, conclui-se que diante do choque dos preceitos constitucionais é óbvio que o interesse difuso e coletivo deve prevalecer sobre o particular, sob o escopo ainda do princípio da razoabilidade. Ainda, importante frisar que, o direito fundamental garantido pelo inciso XIII do artigo $5^{\circ}$ é bastante claro: se é livre para exercer qualquer ofício ou profissão desde que se tenha qualificações profissionais que a lei estabelecer. Ora, no caso em tela, os empresários, proprietários dos cães de guarda não exercem a profissão de guarda ou vigilante, nem propiciam o serviço de alguém qualificado à atividade. $\mathrm{O}$ artigo disciplina o direito de que cada indivíduo possui de exercer uma atividade profissional, de acordo com as suas preferências, possibilidades e de acordo com a lei. 
pôs a natureza - na mesma forma que a fauna - na condição de bem de uso comum do povo e essencial à sadia qualidade de vida.

Ademais, é pacífico o entendimento de que nenhum direito é absoluto, uma vez que podem ser limitados sempre que houver a hipótese de colisão de direitos, como no caso em tela.

Com isso, se reforça o argumento de que animal não corresponde à coisa e nem a objeto está alicerçado em posições teórico-práticas, como as de Lourenço (2008), quando defende nos animais a condição de senciência, capazes de responder às interações entre si e entre homens e animais em suas múltiplas formas, sendo, portanto, seres sencientes, reconhecidos como seres possuídos de valor inerente, descartado o atributo coisa. É nessa linha que a Constituição Brasileira vem se apor, de modo expresso e sem titubear, via seu artigo 225, aos maus-tratos aos animais não humanos, assim como à falta de proteção a flora e a fauna. Medeiros e Albuquerque (2013, p. 22) salientam que a Constituição de 1988 é um marco para o pensamento sobre os direitos animais no Brasil, pois ao vedar a crueldade, o constituinte originário, reconhece ao animal não humano o direito de ter respeitado o seu valor intrínseco, sua integridade, sua liberdade.

Lutar por esses direitos traz uma dimensão de responsabilidade, de compartilhamento, de equilíbrio, já que o colocar-se numa perspectiva de supremacia interespécies, indica uma abordagem antropocêntrica, privilegiando quase que exclusivamente a vida, a qualidade, a dignidade do animal humano. Esse especismo ${ }^{6}$ ainda demarca uma tentativa de supremacia e uma arrogância da espécie humana em relação às demais, como bem pontua Araújo (2003).

É lutando por esse equilíbrio, instável, mas convidativo, que os movimentos sociais e a as mobilizações via redes sociais vêm evidenciando como possibilidades de transformação: trata-se de um dos muitos caminhos.

\footnotetext{
${ }^{6}$ À semelhança da luta contra o racismo e o sexismo, o especismo consiste numa expressão utilizada da década de 1970, que se volta contra a experiência com animais, uma vez que traz prejuízo à espécie.
} 


\subsection{O Papel dos Movimentos Sociais e as Redes Sociais}

O papel dos movimentos sociais e, neles, o de movimentos em rede, tendo como exemplos comunidades formadas em redes sociais, como na rede social denominada como Facebook ${ }^{7}$ são modos de operar que a sociedade de hoje vem mostrando em suas ações e influência, na busca de seus objetos e objetivos.

Não apenas com relação aos movimentos de defesa dos direitos dos animais não humanos, a sociedade vem assistindo a transformações nas relações sociais a partir das mobilizações promovidas pelas ações deflagradas ou amplificadas pelas redes sociais. São processos dinâmicos que geram aglutinações, assim como criam espaços de reverberações sociais e políticas, da mesma forma que criam relações de poder nas microfísicas das relações sociais.

Estudos vêm sendo desenvolvidos de modo mais intenso acerca das mobilizações, criações e expansão de movimentos sociais via redes (WELLMAN; BERKOWITZ,1988; RHEINGOLD, 1996; CASTELLS, 1999; LEVY, 2000; 2002; SCHERER-WARREN, 2005; 2006; AGUIAR, 2007). Nesses estudos são analisados tanto a ação das redes sociais virtuais em termos de interação, quanto a possibilidade de alcance de objetivos coletivos (RHEINGOLD, 1996). Ambientes tecnológicos à disposição de uma grande parcela da população (BRASIL, 2014) vêm favorecendo esse aglutinamento, assim como a mobilização e a amplificação de vozes de atores e de agentes sociais na defesa de direitos. Autores como Levy (2000), Wellman e Berkowitz (1988) destacam o valor das redes sociais virtuais como espaços de aprendizado coletivo, além de promoção de processos cooperativos na criação e difusão tanto de conhecimento quanto de pautas a amplificar em nome desses interesses coletivos. Processos de transformação em curso.

\footnotetext{
${ }^{7}$ Rede social que se constitui num site e um serviço de rede social. Criada por Mark Zuckerberg e lançada a operar em fevereiro de 2004.
} 
As transformações reais, atuais, potenciais e virtuais ${ }^{8}$ (DELEUZE, 1988 ; 1998) da sociedade se manifestam pelo acréscimo da influência e da força das redes sociais (AGUIAR, 2007) ${ }^{9}$. São dinâmicas que se evidenciam tanto pela emergência de novos atores sociais, quanto pela reorganização e surgimento de novas organizações societárias. Essas se fazem presente na sociedade, em função de influências de tecnologias de informação, de processos de informatização que delineiam ações desses novos agentes sociais, assim como da mobilização desses atores para compor novas realidades sociais na contemporaneidade.

\footnotetext{
${ }^{8}$ Os conceitos de real, atual, potencial e virtual tem merecido atenção de pesquisadores. Adota-se, para fins desse trabalho, os entendimentos de Deleuze (1998, p. 173-179), Deleuze (1988, p. 335-346), para quem “[...] o virtual não se opõe ao real, mas ao atual. O virtual possui uma plena realidade enquanto virtual” (DELEUZE, 1988, p. 335). Da mesma forma, “[...] todo objeto é duplo, sem que suas duas metades se assemelhem, sendo uma imagem virtual e, a outra, a imagem atual" (DELEUZE, 1988, p. 337). Ainda, Deleuze (1988, p. 339), em tudo isso, o único perigo é confundir o virtual com o possível. Com efeito, o possível opõe-se ao real; o processo do possível é, pois, uma 'realização'. O virtual, ao contrário, não se opõe ao real: ele possui uma plena realidade por si mesmo. Seu processo é a atualização (DELEUZE, 1988, p. 339). Deleuze (1988, p. 340-341) entende que "[...] o virtual, ao contrário, é a característica da Ideia; é a partir de sua realidade que a existência é produzida, e produzida em conformidade com um tempo e um espaço imanentes à Ideia [...] A atualização do virtual, ao contrário, sempre se faz por diferença, divergência ou diferenciação. A atualização rompe tanto com a semelhança como processo quanto com a identidade como princípio. [...] atualizar-se, para um potencial ou um virtual, é sempre criar linhas divergentes que correspondam, sem semelhança, à multiplicidade virtual".

${ }^{9}$ Sonia Aguiar (2007) pontua, em pesquisa, que “[...] a expressão 'redes sociais na internet' vem sendo utilizada, tanto na mídia quanto em estudos acadêmicos, para se referir indistintamente a tipos de relações sociais e de sociabilidade virtuais que se diferenciam em dinâmicas e propósitos. De um lado, há uma ampla variedade de 'comunidades virtuais' e os chamados sites de redes sociais (Social Network Sites - SNSes, em inglês), cuja existência e desenvolvimento são contingenciados pelo ambiente tecnológico em que são construídos. De outro, inúmeras experiências de redes sociais constituídas nas práticas cotidianas e nas lutas sociopolíticas do 'mundo real', que utilizam a Internet como um ambiente de interação e/ou um espaço público complementar. Por sua complexidade e abrangência, com vínculos que não se delimitam às fronteiras geográficas e culturais (etnias, religião, idioma, gênero etc.), essas novas formas relacionais e suas diferentes possibilidades de apropriação das tecnologias de informação e comunicação (TICs) representam um desafio teórico e metodológico para as tradicionais técnicas de Análise das Redes Sociais (ARS)".
} 
Desse modo, grupos dentro de redes sociais, como Facebook, por exemplo, criam comunidades que fazem defesa de atos em prol de animais, no caso, a favor da qualidade de vida dos hoje denominados como cães de aluguel. Como exemplo disso há este link <https://www.facebook.com/contracaesdealuguel $>$. São comunidades fluidas, "a-centradas", abertas à participação, além de extremamente atuante em termos de uma militância.

É possível afiançar as redes sociais como condições específicas de espaço-tempo variáveis na composição, extensão e amplificação de relações entre pessoas, mediadas ou não por sistemas informatizados (AGUIAR, 2007). Segundo Aguiar (2007), essas mesmas relações, em ambientes virtuais ou não, trabalham com interesses coletivos ou individuais e mesmo sociopolíticos de organizações, com vistas a possíveis mudanças na vida das pessoas, do coletivo ou das organizações ou de instituições. $\mathrm{O}$ uso dos ambientes virtuais agrega fator e valor às trocas, de alguma maneira, seja pela velocidade, seja pela instantaneidade. Como bem se defende, como destaca Castells (1999), esses espaços de interação social virtuais favorecem, além da comunicação que se estabelece quase que instantaneamente entre os usuários, a descentralização da informação, uma vez que a territorialidade seja pensada numa outra perspectiva. Tais espaços compõem, desse modo, novos modos de composição de uma esfera pública, uma vez que se abrem para possibilidade de construção de informações e de defesas de pontos de vista entre diferentes e múltiplos atores e agentes sociais.

A esfera pública pode ser visualizada em Habermas (1997, p. 92$93)^{10}$ e vem defender a construção de novos patamares de cidadania e de

\footnotetext{
${ }^{10}$ Esfera pública aqui entendida como espaço de ressonância das vontades populares e coletivas que se fazem valer via um princípio de soberania e de construção da vontade popular (HABERMAS, 1997, p.92-93). “A esfera ou espaço público é um fenômeno social [...] pode ser descrita como uma rede adequada para a comunicação de conteúdo, tomadas de posição e opiniões; nela os fluxos comunicacionais são filtrados e sintetizados a ponto de se condensarem em opiniões públicas enfeixados em temas específicos [...] podemos dar uma forma abstrata e perene a essa estrutura espacial de encontros simples e episódicos, fundada no agir comunicativo, e estende-la a um grande público de presentes. [...] quanto mais elas se desligam de sua presença física, integrando também, por exemplo, a presença virtual de leitores situados em lugares distantes, [...] tanto mais clara se torna
} 
autonomia cidadã. Essa esfera se potencializa e, nela, os atores buscam se fazer presente e fortes na criação, formulação e implementação de políticas de Estado ${ }^{11}$, da mesma forma que políticas públicas e sociais. No presente estudo, busca-se analisar - diante dos ganhos e perdas em torno da questão de uso indébito de animais não humanos na vigilância e segurança - a dinâmica dos movimentos sociais em sua relação com as políticas públicas e sociais para, a partir dessas e de outras ações correlatas, ver transformações sociais na sociedade brasileira que a contemporaneidade nos apresenta em múltiplos movimentos sociais, quais sejam, as possibilidades de outro mundo possível em termos de direito dos animais. Evidencia, assim, novos patamares de participação social, já que a ideia de rede e de movimentos sociais (SCHERER-WARREN, 2006) é assumida para detectar os rumos das ações, uma vez que esses movimentos sociais contribuem para a consolidação de espaços democráticos, de envolvimento cidadão e de ganhos em direitos humanos e sociais.

Modos de operar dessas redes conduziram, neste estudo, tanto a auxiliar no veto e consequente modificação de uma Proposta de Lei em apoio aos prestadores de serviço de vigilância com cães de aluguel. Em decorrência de mobilizações fortes na área, no município e no Estado do Rio Grande do Sul, no caso, Secretaria de Direito dos Animais (SEDA) e

abstração que acompanha a passagem da estrutura espacial das interações simples para a generalização da esfera pública".

${ }^{11}$ Não é à toa que a Secretaria-Geral da Presidência da República (SG-PR) e universidades, como UFRJ, desenvolvem pesquisa "Movimentos Sociais e Esfera Pública - Impactos e desafios da participação da sociedade civil na formulação e implementação de políticas governamentais". O objetivo dessa política é “[...] compreender a dinâmica dos movimentos sociais na sua relação com as políticas públicas do governo federal, buscando também entender as transformações sociais na sociedade brasileira contemporânea. Os movimentos sociais estudados são: rurais, urbanos, negro, indígena, quilombolas, LGBTs, sindical, de mulheres e de juventude". Ainda, conforme dados da SG-PR, “[...] outros dois exemplos dos encaminhamentos adotados pela Secretaria-Geral nesse sentido é o desenvolvimento de uma metodologia de monitoramento das pautas dos movimentos sociais, em fase de construção; o portal Participa.br, já no ar na versão beta; bem como a Política e o Sistema Nacional de Participação Social, a serem lançados pelo governo federal". Disponível em: <www.brasil.gov.br/governo/2014/04/pesquisa-analisa-relacaoentre-movimentos-sociais-e-estado $>$. Acesso em: dia, mês e ano????. 
Assembleia Legislativa, respectivamente, essa possibilidade, heterogênea na sua base, participativa, agregadora, permitiu pensar a diferença.

Com esse entendimento, independentemente da heterogeneidade, sob uma capa de homogeneidade, investe-se na potencialização, pela rede e na rede, de sujeitos coletivos que se agrupam em torno de alguns valores, de objetivos e "bandeiras". Indicam projetos que se fazem comum para, então, buscar alterar uma realidade, nesse momento ainda num campo virtual de realidade. São articulações e rearticulações contínuas até a construção de uma soberania da vontade popular (Habermas, 1988). Sem buscar uma identidade única e muito menos uma homogeneidade falsa, esses atores sociais se territorializam e se desterritorializam múltiplas vezes, como desafia Deleuze (1998), para a criação dessas políticas sociais, no caso, de proteção aos animais não humanos. São algumas dessas ações destacadas neste estudo que mostram a força dessas redes, virtuais ou não, sob as mais diferentes formas organizacionais que dão corpo possível a uma realidade pretendida, como parte de espaço para formação e organização de grupos e ações coletivas.

Autores como Melucci (1996) e Scherer-Warren (2006) destacam, dentro de espaços descentrados, a centralização de argumentos que mobilizava os atores sociais e agentes públicos como foco de reivindicações e esforços concentrados: na década de 1970 se faziam presente movimentos reivindicatórios em geral em termos de trabalho; a década de 1980 assiste ao que se denomina como enfoque em processos de autonomia; já a década de 1990 vem contribuir, associada a movimentos da própria sociedade, a defesas pela cidadania. Aguiar (2007) apresenta outros focos a esse processo de mobilização coletiva, que envolvem temáticas vinculadas ao ambiente e ao desenvolvimento social. Essa vertente de defesa ao meio ambiente, em seus múltiplos conceitos e abrangência, marca uma posição típica da década de 2000. O século XXI se mostra sensível à vida e à qualidade de vida na terra. Direitos Humanos e sociais passam a ser referência nesses movimentos em rede. $\mathrm{Na}$ década próxima ao ano de 2010 , e nela própria, inicia-se mais fortemente uma vertente vinculada à defesa do ambiente em termos de direitos dos animais. Scherer-Warren (2005) desafia a melhor entender esse envolvimento de atores sociais em rede 
como uma expressão de atores políticos em ação, criando políticas sociais e públicas, além de estabelecer ganhos de qualidade de vida.

Segundo Scherer-Warren (2006), esses movimentos sociais se constituem por serem heterogêneos, contínuos, descentrados, plurais e democráticos em seus objetos, articulados, geralmente, com diferentes grupos entre si. A autora Scherer-Warren (2006) destaca uma subdivisão entre direitos humanos clássicos e direitos humanos apresentados como de uma nova geração, que privilegiam e focam em minorias e questões ambientais numa defesa contra a exclusão e a violência, seja de que ordem for. São redes que se formam num campo atual ou virtual, entre diferentes atores sociais quase sempre em tensão continuada com vistas a participar para a formulação e a implementação de políticas sociais e públicas, constituindo-se como agentes de pressão autônoma da sociedade organizada. Há, também, o destaque Scherer-Warren (2006) ${ }^{12}$ desses movimentos sociais, parte que são por se constituírem em mobilizações em redes, espaços não só de descentralização e de democracia. Neles, também, se fazem presentes jogos de relações de poder, nos quais as microfísicas de poder podem se exercer de forma intensa. São jogos de relações de poder que se fazem presente e que desestabilizam e desterritorializam potências de agir e de provocar transformações sociais de porte.

No caso, as redes, merece ser frisado, assume, pela sua própria natureza, ambientes rizomáticos (DELEUZE; GUATTARI, 1995), acentrados, sem hierarquia, razoavelmente livres, com múltiplas entradas e saídas, sem níveis identitários e com uma ação de transversalidade (SCHERER-WARREN, 2006). Muito mais sujeitos plurais, agenciamentos coletivos que se organizam em direção às pautas de mobilização contra processos de exclusão e violência. Processos continuados de ar-

\footnotetext{
${ }^{12}$ Scherer-Warren (2006) defende e busca traçar algumas categorias a esses movimentos sociais, quais sejam: "várias dimensões definidoras de um movimento social (identidade, adversário e projeto):unem-se pela força de uma identidade étnica (negra) e de classe (camponeses pobres) - a identidade; para combater o legado colonialista, o racismo e a expropriação - o adversário; na luta pela manutenção de um território que vive sob constante ameaça de invasão, ou seja, pelo direito à terra comunitária herdada - o projeto." Assim, independente do foco, há um foco agregador, algo a combater e um adversário para focar lutas e resultados.
} 
ticulação e de luta, dentro dos antagonismos presente nas redes em sua complexidade, potencializam a afirmação de que as redes estão, sempre, repletas de conflito, de tentativa de verticalização, de retorno a uma homogeneização, da mesma forma que pelas condições de múltiplos nós, de descentralização, de falta de hierarquia congelante e paralisadora, estando a afirmar uma potência de agir ligada à empatia, à compaixão, à tolerância, à reciprocidade e à solidariedade (HABERMAS, 1997; DELEUZE, 1996; DELEUZE; GUATTARI, 1995).

Voltando-se aos alcances dessas mobilizações, detectam-se resultados de criação dessas leis em diversos municípios brasileiros, como Curitiba e o próprio Estado do Paraná, que detém lei desde 2008 e 2009 respectivamente; em São Paulo, Santos tem lei equivalente e no Estado de São Paulo, além de movimento no próprio legislativo estadual uma gama enorme de municípios estuda implantação de Lei proibitiva, fazendo, entretanto, regulamentação dessas atividades. São ganhos parciais. Minas Gerais tenta desde 2011 implantar lei equivalente ao do Paraná e Rio Grande do Sul. São lutas que são geradas e alimentadas no seio da sociedade, forçando o Direito a se comportar de uma maneira diferenciada, abrindo os olhos e desvelando as questões de justiça além do animal humano.

Após mobilizações, movimentos intensos no Legislativo, no Executivo via SEDA, Secretaria criada para o Direito dos Animais em Porto Alegre, a comunidade de proteção aos animais não humanos conseguem o registro dessa conquista via aprovação e publicação, com posterior sanção do Governador do Estado, da Lei n.14.229, de 15 de abril de 2013, publicada no DOE n. 072, de 16 de abril de 2013, que entra em vigor para disciplinar, ao mesmo tempo em que demarca a proibição, da prestação dos serviços de vigilância, segurança ou guarda patrimonial e pessoal, através da utilização de cães de guarda. Uma defesa compatível com a mais moderna interpretação das normas constitucionais e infraconstitucionais de proteção do animal não humano no Brasil.

Um exame das denúncias, como detalhamento dos direitos dos animais, assim como uma análise crítica das propostas de lei, contrabalançadas e enriquecidas por mobilizações em rede, permitiu que a atual lei definida no Rio Grande do Sul fosse mais detalhada e profunda em relação à qualidade de vida. 
Buscou-se, assegurar, de igual forma, que os animais não humanos em questão tivessem assegurados sua condição de vida, uma vez que as empresas do setor, muitas vezes, fazem o que denominam "exclusão" do animal, via um desligamento, às vezes, de descarte, morte. Assim, como já previsto em Lei Estadual de n. 13.193/2009 que disciplina ações dessas e de outras empresas nos cuidados com a vida, ficando vedado, sob pena de crime, o extermínio ${ }^{13}$.

Nessa linha, Espinosa (DELEUZE, 1996, p. 265) desafia com a denúncia das potências opressivas, provocando impotências. Inclusive, Deleuze, em seu estudo acerca de Espinosa (1996) destaca que certas paixões tristes, desmobilizadoras, como, a esperança, a humildade, o medo, e, inclusive, o arrependimento e até a ideia de segurança, acabam por despotencializar ações que nos mobilizam para transformações. Segundo Deleuze (1996, p. 265), "[...] uma cidade é tanto melhor quanto mais se apoia sobre afecções alegres; o amor à liberdade deve superar a esperança, o medo e a segurança [...]", dando margem, então a uma luta pela continuada mobilização e o aumento de potência de atuar, uma afirmação da vida. Com isso, emergem novos sujeitos sociais e coletivos, assim como novos ou outros cenários políticos abertos ao direito, à liberdade e à vida.

Contudo, essa transformação não é pacífica, não é tranquila em todos os nichos da sociedade. Desconfortável e indignado com a elaboração legislativa, o Sindicato das Empresas de Segurança e Vigilância do RS (SIDDESP) ajuizou uma Ação Declaratória de Inconstitucionalidade, sustentando vício de origem da legislação, uma vez que competência legislativa seria da União e não do Estado, uma vez que alegaram que a Lei estaria invadindo a competência estabelecida no art. 22, I da Constituição Federal.

Em sede de análise do Tribunal de Justiça do Estado do Rio Grande do Sul (TJRS), o Desembargador relator, a nosso ver, de forma equivoca-

${ }^{13}$ Lei Estadual n. 13.193/2009, disciplina que: “Art. $2^{\circ}$ Fica vedado o extermínio de cães e gatos pelos órgãos de controle de zoonoses, canis públicos e estabelecimentos oficiais congêneres, à exceção das universidades e dos institutos com fins de ensino, pesquisa e estudos científicos. $\S 1^{\circ}$ A eutanásia, permitida nos casos de enfermidades em situação de irreversibilidade, será justificada por laudo do responsável técnico pelos órgãos e estabelecimentos referidos no "caput" deste artigo, precedido de exame laboratorial, facultado o acesso aos documentos por entidades de proteção dos animais". 
da e limitada, entendeu que de fato o Estado do Rio Grande do Sul havia invadido a competência legislativa da União ao legislar sobre questões vinculadas a atividade laboral. E, assim, concedeu uma liminar suspendendo a efícácia da norma.

Em sede de recurso, a temática retornou ao TJRS e o Desembargador relator, Marcelo Bandeira Pereira, mantem o entendimento anteriormente sustentado e defende que (ADIN n. 70060888492, 2014, p. 12)

Por obediência ao pacto, não é dado ao Constituinte Derivado Decorrente inovar na ordem jurídica em matéria de competência. É dizer, não compete aos estados-membros fixarem suas competências para além daquelas dispostas na Constituição Federal, nem invadindo o que é competência da União, nem o que é de competência dos Municípios. Pelo contrário, a competência dos estados-membros é estabelecida por exclusão às demais.

Como anteriormente referido: "Trata-se de princípio estabelecido implícito vedatório, na medida em que o campo do Estado está jungido às matérias que não foram dadas à União, de forma exclusiva ou privativa (como no caso), ou aos Municípios". A conclusão, portanto, não pode ser diferente da que já manifestada, no sentido de que "a atuação legislativa estadual que desborda dos limites estabelecidos pelo Constituinte Derivado Decorrente, viola a Constituição Estadual, viabilizando a concessão de medida liminar para imediata sustação da legislação em cotejo.

Contudo, a questão não se revelou pacífica nem mesmo entre os pares, o Desembargador Redator, Luiz Felipe Silveira Difini (ADIN n. 70060888492, 2014 p. 20) defende que

Com efeito, a Lei Estadual n. 14.229, de 15 de abril de 2013, que dispõe sobre a proibição de prestação de serviços de vigilância de cães de guarda com fins lucrativos nos âmbito do Estado do Rio Grande do Sul não se imiscui, a meu sentir, em matéria que refoge à sua competência. Pelo contrário. Consoante o que dispõe o art. 24 da Constituição Federal compete à União, aos Estados e ao Distrito Federal legislar concorrentemente sobre: VI-florestas, caça, pes- 
ca, fauna, conservação da natureza, defesa do solo e dos recursos naturais, proteção do meio ambiente e controle da poluição;

Pois bem. Do exame da legislação impugnada, verifica-se que esta pretendeu empreender proteção relativamente à exploração de animais, por prestação de serviços de vigilância de cães de guarda com fins lucrativos, não se tratando de mero regramento tendente a disciplinar matéria relativa à atividade econômica, como quer fazer crer a parte recorrida.

Ora, admitindo que a referida legislação em análise de controle abstrato de constitucionalidade trata de proteção ambiental, não se está mais fazendo referência à regulação de atividade econômica - competência privativa da União - mas sim da proteção do ambiente como um todo, nele incluída a fauna - competência legislativa concorrente.

O voto do Desembargador Redator gerou o pedido de vista do Desembargador Francisco José Moesch (ADIN 70060888492, 2014, p. 31), que passou a defender que

Da leitura da Lei $\mathrm{n}^{\circ}$ 14.229/2013 e respectiva justificativa é possível concluir que seu desiderato não foi o de regular uma relação de Direito Civil e Comercial - prestação de serviços (atividade de vigilância animal), mas sim o de proteger os animais (cães de guarda) que são locados e, recorrentemente, submetidos a maus tratos, conforme inúmeros registros de reclamações efetuadas por entidades de proteção aos animais. A doutrina ambientalista tem reconhecido a existência de uma dignidade da vida não-humana e dos animais, especialmente diante dos novos valores ecológicos que passam a modular as relações sociais contemporâneas.

Medeiros (2013, p. 255) sustenta que sob os auspícios do principio da dignidade da vida, "[...] conclui-se pela existência de um dever fundamental de proteção aos animais não humanos e de um dever do Estado em relação aos mesmos". Medeiros (2013, p. 255) destaca, ainda, que "[...] em face do reconhecimento da aplicação do princípio da dignidade da vida e da consideração dos animais não humanos como membros de 
uma comunidade moral, é possível concluir pelo reconhecimento de um direito a ser protegido".

No caso em tela, lucidamente, o voto do Desembargador Francisco Moesch defende que a matéria é de competência legislativa concorrente, não havendo usurpação de competência privativa da União, revogando, portanto, a liminar. Os votos dos desembargadores Difini e Moesch foram decisivos para uma mudança de paradigma no que concerne a defesa dos animais não humanos. Por maioria de 13 votos a 11, o órgão Especial do Tribunal de Justiça do Estado do Rio Grande do Sul derrubou a liminar que suspendia a Lei Estadual n. 14.229/13, estando, portanto, a norma em vigor.

\section{Conclusão}

Assim, conforme bem salienta Regan (1989), os animais não existem em função do homem: eles possuem uma existência, um valor próprios. Uma moral que não incorpore essa verdade é vazia. Um sistema jurídico que a exclua é cego. Nessa linha, serve-se das teses defendidas por Primatt (1976) de que: a) as tradições nem sempre são sinônimas de ética, nem sempre preservam valores morais universais; b) as funções públicas implicam autoridade moral e quem exerce uma função na esfera pública tem o dever moral de combater toda forma de discriminação e de preconceito, pois esses expressam a violência das interações humanas que seguem modelos estabelecidos na tradição; e c) o dever humano mais sagrado, relativamente aos animais, de não interferência quando isso representa um malefício, equivale, na prática, ao dever de deixa-los viver em paz.

Portanto, torna-se inaceitável que uma legislação elaborada pelo Poder Público, pelo Estado na sua função legiferante, estabeleça discriminação e preconceito, por meio do especismo, enaltecendo a não valorização da vida, ao tratar seres vivos, portadores de valor inerente e inclusos em comunidades morais, como coisas/objetos.

Papel das redes e grupos, assim como de agentes públicos legislativo, do executivo e do judiciário é determinante para ocorrer a virada ético-normativa em defesa do bem comum. Há que se enxergar um reconhecimento do princípio da dignidade além da vida humana e esse movimento já começou. 


\section{Referências}

AGUIAR, Sonia. Redes sociais na internet: desafios á pesquisa. In: XXX CONGRESSO BRASILEIRO DE CIÊNCIAS DA COMUNICAÇÃO. Santos, intercom, 2007. Anais.... Santos: Intercom, 2007. p. 1-15. Disponível em: $<$ http://www.sitedaescola.com/downloads/portal_aluno/ Maio/Redes sociais na internet: Desafios pesquisa.pdf $>$. Acesso em: 3 maio 2015.

ARAÚJO, Fernando. A hora dos direitos dos animais. Coimbra: Almedina, 2003.

BRASIL. Pesquisa analisa relação entre movimentos sociais e Estado. Brasília, DF: Senado Federal, [2014]. Disponível em: <www.brasil.gov. br/governo/2014/04/pesquisa-analisa-relacao-entre-movimentos-sociaise-Estado $>$. Acesso em: 3 de maio de 2015.

BRASIL. Tribunal de Justiça do Estado do Rio Grande do Sul. ADI n. 70060888492. Des. Relator Marcelo Bandeira Pereira. Disponível em: $<$ http://www.tjrs.jus.br/busca/?tb=proc $>$. Acesso em: 2 maio de 2015. CASTELLS, Manuel. A sociedade em rede. São Paulo: Paz e Terra, 1999. DELEUZE, Gilles. Diálogos: Gilles Deleuze, Claire Parnet. São Paulo: Ed. Escuta, 1998.

DELEUZE, Gilles. Diferença e repetição. Rio de Janeiro: 1988.

DELEUZE, Gilles. Spinoza y el problema de la expressión. Barcelona: Atajos, 1999.

DELEUZE, Gilles; GUATTARI, Félix. Capitalismo e esquizofrenia. Rio de Janeiro: Ed. 34, 1995. p. 11-16, v. 1.

DONALDSON, Sue; KYMLICKA, Will. Zoopolis: a political theory of animal rights. Oxford: Oxford University Press, 2013.

ECO AGÊNCIA. Notícias ambientais. Vigora no RS a proibição do aluguel de cães de guarda. [2015]. Disponível em: $<$ http://www. ecoagencia.com.br/?open=noticias\&id=VZISXRVVONVTVFzMT1WN XJFbKVVVB1TP>. Acesso em: 5 abr. 2015. 
FELIPE, Sônia T. Ética e experimentação animal: fundamentos abolicionistas. Florianópolis: Editora da UFSC, 2014.

FELIPE, Sônia T. Ética e experimentação animal: fundamentos abolicionistas. Florianópolis: Editora da UFSC, 2008.

FOUCAULT, Michel. La vida de los hombres infames. Madrid: La Piqueta, 1990.

GORDILHO, Heron José de Santana. Abolicionismo Animal. Salvador: Evolução, 2008.

HABERMAS, Jürgen. Direito e democracia, entre facticidade e validade II. Rio de Janeiro: Tempo Brasileiro, 1997.

HABERMAS, Jürgen. O futuro da natureza humana. Rio de Janeiro: Martins Fontes, 2004.

LEVAI, Laerte Fernando. O direito dos animais. Campos do Jordão: Mantiqueira, 2004.

LÉVY, Pierre. Cibercultura. São Paulo: Editora 34, 2000.

LÉVY, Pierre. Ciberdemocracia. Trad. Alexandre Emílio. Lisboa: Instituto Piaget, 2002.

LOURENÇO, Daniel Braga. Direito dos Animais: fundamentação e novas perspectivas. Porto Alegre: Sérgio Antônio Fabris Editor, 2008. p. 393.

MACHADO, Joice. Ribeiro; TIJIBOY, Ana Vilma. Redes Sociais Virtuais: um espaço para efetivação da aprendizagem cooperativa.

Novas Tecnologias na Educação. CINTED-UFRGS, Porto Alegre, v. 3, n. 1, maio, 2005. Disponível em: <http://seer.ufrgs.br/renote/article/ view/13798/7994> . Acesso em: 5 maio 2015.

MEDEIROS, Fernanda Luiza Fontoura de. Direito dos animais. Porto Alegre: Livraria do Advogado, 2013.

MEDEIROS, Fernanda Luiza Fontoura de. Meio Ambiente: direito e dever fundamental. Porto Alegre: Livraria do Advogado, 2004.

MEDEIROS, Fernanda Luiza Fontoura de; ALBUQUERQUE, Leticia. Constituição e Animais não humanos: um impacto no Direito Contemporâneo. In: CONPEDI/UNINOVE; Sociedade Global 
e seus impactos sobre o estudo e a afetividade do Direito na contemporaneidade. Coordenadores: Maria Cláudia da Silva Antunes de Souza, Celso Antonio Pacheco Fiorillo, Consuelo Yatsuda Moromizato Yoshida. 1. ed. Florianopolis: FUNJAB, 2013. p. 134-158, v. II.

MELUCCI, Alberto. Challenging codes: collective action in the information age. New York: Cambridge University Press, 1996.

NACONECY, Carlos. Ética \& Animais: um guia de argumentação filosófica. Porto Alegre: EdiPUCRS, 2014.

NUSSBAUM, Martha C. Para além da compaixão e humanidade justiça para animais não-humanos. In: MOLINARO, Carlos Alberto et al. (Org.). A dignidade da vida e os direitos fundamentais para além dos humanos: uma discussão necessária. Belo Horizonte: Fórum, 2008. p. 85-126.

PRIMATT, Humphrey. A dissertation on the duty of mercy and sin of cruely to brute animals. London: Kessinger Publishing, 1976.

REGAN, Tom. Human rights. North Caroline: North Caroline University Press, 1983.

REGAN, Tom. The case for animal rights. Berkley: University of California Press, 1989.

RHEINGOLD, Howard. Comunidade virtual. Lisboa: Gradiva, 1996. RIO GRANDE DO SUL. Governo do Estado. Lei n. 14.229, de 15 de abril de 2013. Que proíbe a prestação de serviços de vigilância de cães de guarda com fins lucrativos no âmbito do Estado do Rio Grande do Sul e dá outras providências. [2013a]. Disponível em: $<$ http://www. legislacao.sefaz.rs.gov.br/Site/Document.aspx?inpKey=221230\&inpCod Dispositive $=\& i n p D s K e y w o r d s>$. Acesso em: 5 abr. 2015.

RIO GRANDE DO SUL. Governo do Estado. Lei n. 14.268, de 18 de julho de 2013. [2013b]. Disponível em: $<$ http://www.legislacao.sefaz. rs.gov.br/Site/Document.aspx inpKey $=221230 \&$ inpCodDispositive $=\&$ in pDsKeywords>. Acesso em: 5 maio 2015. 
ROLLIN, Bernard E. Animal Rights \& Human Morality. New York: Prometeus, 2006

SCHERER-WARREN, Ilse. Das mobilizações às redes de movimentos sociais. Sociedade e Estado, Brasília, DF, v. 21, n. 1, jan.-apr., 2006. Disponível em: <http://dx.doi.org/10.1590/S0102-69922006000100007>. Acesso em: 6 maio 2015.

SCHERER-WARREN, Ilse. Redes sociales y de movimientos en la sociedad de la información. Nueva Sociedad, Venezuela, n. 196, mar.abr. 2005.

SMITH, Adam. The theory of moral sentiments. New York: Modern Library, 1937.

SOUZA, Ricardo Timm de. Ética e animais - Reflexões desde o imperativo da alteridade. In: MOLINARO, Carlos Alberto et al. (Org.). A dignidade da vida e os direitos fundamentais para além dos humanos: uma discussão necessária. Belo Horizonte: Fórum, 2008. p. 47-48.

SUNSTEIN, Cass R. NUSSBAUM, Martha C. Animal Rights: currents debates and new directions. Oxford: Oxford University Press, 2004.

WAAL, Frans de. A era da empatia: lições da natureza para uma sociedade mais gentil. São Paulo: Companhia das Letras, 2010.

WELLMANN, Barry; BERKOWITZ, Scott Darrell. Social Structures: a Network Approach. Administrative Science Quarterly, New York: Sage Publications/Cornell University, v. 35, n. 4, p. 746-748, Dec. 1990.

Fernanda Luiza Fontoura de Medeiros é professora permanente do Programa de Pós-Graduação em Direito e Sociedade do Centro Universitário La Salle (UNILASALLE); pesquisadora do CNPq; coordenadora da pesquisa agraciada com fomento pelo Edital Universal MCTI/CNPq n. 14-2013, intitulada "Proteção dos animais não-humanos: análise da jurisprudência brasileira"; doutora em Direito pelo Programa de Pós-Graduação em Direito da Universidade Federal de 
Santa Catarina (UFSC) - doutoramento sanduiche pela Faculdade de Direito da Universidade de Coimbra; mestre em Direito pelo Programa de Pós-Graduação em Direito da Pontifícia Universidade Católica do Rio Grande do Sul (PUCRS); professora adjunta da Faculdade de Direito da Pontifícia Universidade Católica do Rio Grande do Sul (PUCRS); líder do grupo de pesquisa cadastrado no CNPq intitulado "Direito, Ambiente e Novas Tecnologias"; e presidente do Instituto Piracema - Direitos Fundamentais, Ambiente e Biotecnologias.

E-mail: fernanda.medeiros@unilasalle.edu.br/fernanda.medeiros@pq.cnpq.br Endereço profissional: Pontifícia Universidade Católica do Rio Grande do Sul, Faculdade de Direito, Avenida Ipiranga, n. 6.681, prédio 11, Partenon, Porto Alegre, RS. CEP: 90619-900.

Leticia Albuquerque é professora adjunta III dos cursos de Graduação e PósGraduação em Direito da Universidade Federal de Santa Catarina, doutora em Direito pelo Programa de Pós-Graduação em Direito da Universidade Federal de Santa Catarina (UFSC) - doutoramento sanduiche pela Faculdade de Direito da Universidade de Coimbra; mestre em Direito e Relações Internacionais pelo Programa de Pós-Graduação em Direito da Universidade Federal de Santa Catarina (UFSC); líder do grupo de pesquisa cadastrado no $\mathrm{CNPq}$ intitulado "Observatório de Justiça Ecológica"; e membro do Conselho Nacional do Meio Ambiente (CONAMA).

E-mail: leticia.albuquerque@ufsc.br/laetita.ufsc@gmail.com

Endereço profissional: Universidade Federal de Santa Catarina, Centro de Ciências Jurídicas, Campus Universitário, Trindade, Florianópolis, SC. CEP: 88040-900. 
